\title{
Correction to: No-Notice Mystery Patient Drills to Assess Emergency Preparedness for Infectious Diseases at Community Health Centers in New York City, 2015-2016
}

\author{
Mohsin Ali ${ }^{1,2,3,4}$ D . Marsha D. Williams ${ }^{1}$
}

Published online: 19 February 2019

(c) The Author(s) 2019

\section{Correction to: Journal of Community Health https://doi.org/10.1007/s10900-018-00595-5}

The article No-Notice Mystery Patient Drills to Assess Emergency Preparedness for Infectious Diseases at Community Health Centers in New York City, 2015-2016, written by Mohsin Ali and Marsha D. Williams, was originally published electronically on the publisher's internet portal (currently SpringerLink) on 02 January 2019 without open access.

With the author(s)' decision to opt for Open Choice the copyright of the article changed on 13 January 2019 to $($ ) The Author(s) 2019 and the article is forthwith distributed under the terms of the Creative Commons Attribution 4.0 International License (http://creativecommons.org/licenses/ by/4.0/), which permits use, duplication, adaptation, distribution and reproduction in any medium or format, as long as you give appropriate credit to the original author(s) and the source, provide a link to the Creative Commons license and indicate if changes were made.

The original article can be found online at https://doi.org/10.1007/ s10900-018-00595-5.

Mohsin Ali

mohsin.ali@childrens.harvard.edu; mohsinali90@gmail.com

1 Bureau of Healthcare System Readiness, Office of Emergency Preparedness and Response, New York City Department of Health and Mental Hygiene, Queens, NY, USA

2 Icahn School of Medicine at Mount Sinai, New York, NY, USA

3 Department of Medicine, Boston Children's Hospital, 300 Longwood Avenue, Hunnewell 2, Boston, MA 02115, USA

4 Department of Pediatrics, Boston Medical Center, Boston, MA, USA
Publisher's Note Springer Nature remains neutral with regard to jurisdictional claims in published maps and institutional affiliations. 